\title{
Reseña del libro A lomo de mula. Viaje al corazón de las FARC de Alfiredo Molano*
}

\section{Hilderman Cardona-Rodas}

Estudiantes del pregrado en Ciencia Política

Universidad de Medellín, Medellín, Colombia hcadona@udem.edu.co

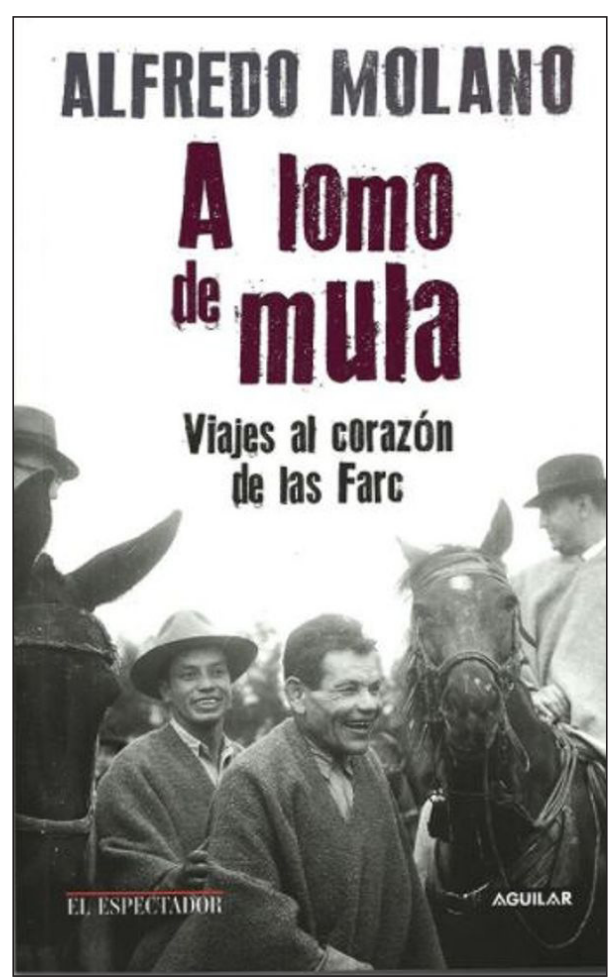

Cubierta del libro A lomo de mula.

Viajes al corazón de las FARC Fuente: Molano, A. (2016).

Alfredo Molano escribe desde la polifonía de las experiencias de la guerra en Colombia. Cada uno de sus relatos explora, desde la subalternidad, las huellas de la violencia y el teatro de la crueldad y el dolor que ha significado el conflicto

Cómo citar: Cardona-Rodas, H. et al. (2019). Reseña del libro A lomo de mula. Viaje al corazón de las FARC de Alfredo Molano. Ciencias Sociales y Educación, 8(15), 301-305. DOI: http://10.22395/csye.v8n15a17

Recibido 13 de marzo de 2019

Aprobado: 23 de abril de 2019. 
armado colombiano. Por ello, el libro A lomo de mula. Viaje al corazón de las Farc, publicado en 2016, es un vivo ejemplo del compromiso de la crítica en el acto político de la escritura. Molano, sociólogo y periodista, relata en su libro las condiciones de posibilidad y existencia del nacimiento del movimiento guerrillero Farc. En 1965 este grupo despliega su accionar militar insurgente producto de la arremetida del ejército colombiano ordenada por el entonces presidente Guillermo León Valencia (1962-1966) del Frente Nacional contra lo que se denominaba "República Independiente de Marquetalia", ubicado en el corregimiento de Gaitania, municipio de Planadas del departamento del Tolima, conformada por un grupo de campesinos liderados desde una concepción comunista por Pedro Antonio Marín Marín, conocido como Manuel Marulanda Vélez o Tirofijo, y Luis Alberto Morantes Jaimes, conocido como Jacobo Arenas. Marín y Morante serían los fundadores y comandantes de las Fuerzas Armadas Revolucionarias de Colombia que estuvo activa durante más de 50 años contra el gobierno colombiano hasta su transformación como partido político en el proceso de paz que llevó a cabo la presidencia de Juan Manuel Santos (2010-2018).

Cuando leí por primera vez el libro de Molano me encontraba en el corazón de un cultivo de hortalizas. Durante varios días sentipensé las palabras encarnadas que el libro arrojaba a mi piel. Cada relato fue la expresión del juego dialéctico del estremecimiento ante la historia política de Colombia ligada a la inequidad, la pobreza, la avidez corrupta del poder, la distribución inequitativa de la tierra y la producción social de la ignorancia. Por ello, cada testimonio que reporta Molano constituye un espacio de enunciación de aquello que Wittgenstein reflexiona sobre la posibilidad de ser afectado por el dolor en cuerpo ajeno. La comunicabilidad del sufrimiento, más allá de una función morbosa, convoca a las fuerzas expresivas del lenguaje en un nosotros corpoafectante. En el trascurso de la lectura vivía toda expresión como un latido de las cosas que me acompañaban, el sonido de las vacas, de los caballos, los gatos y el cacareo de las gallinas junto con el vaivén de los árboles. La sensación hiperestésica desarreglaba todos mis sentidos en aquella polifonía que teatraliza la narrativa de Alfredo Molano.

Para el número 15 de la revista Ciencias Sociales y Educación convoqué en comunión de la palabra a mis estudiantes del curso Historia de los imaginarios políticos del pregrado en Ciencia Política de la Universidad de Medellín a conversar sobre A lomo de mula. Viaje al corazón de las Farc, y he aquí el resultado: una escritura compartida ante el vértigo de la imagen dialéctica en cada pasaje epidérmico del libro de Molano. 


\section{El corazón de las Farc y la historia contemporánea de Colombia Esteban Rodríguez Sánchez}

El trabajo de Molano, su reconstrucción de la historia es, ante todo, un volver a los testimonios más cercanos del conflicto. Molano es un autor fundamental para entender el conflicto armado colombiano. Ignorar esta labor es, cuanto menos, estúpido. En el proceso de creación de este texto, con un grupo de amigos (y a petición del profesor) nos dirigimos al Museo Casa de la Memoria. Allí, el texto introductorio de la Sala Central Medellín, Memorias de Violencia y Resistencia me recordó inmediatamente a Molano. Dicho texto dice: "No existe una Verdad. No hay una historia completa. Cada uno narra, desde su punto de vista, el rol que ha desempeñado en el entramado. Y al entrecruzarse, lo relatos se transforman, se enriquecen, se complejizan". Aquellos que se dedican a la historia tradicional, se limitan únicamente a memorizar fechas de eventos grandes y "relevantes". Molano parte de lo concreto, de los relatos de las personas que sufrieron (y sufren) la miseria causada por el conflicto y, a partir de ahí, reconstruye esos eventos grandes. Molano narra, con increíble destreza, la Colombia que "las mayorías" ven, no quieren ver o no dejan que se vea (Molano, 2016). Esto recuerda a la tercera tesis sobre el concepto de historia de Walter Benjamin cuando dice:

El cronista que narra los acontecimientos sin distinguir entre los grandes y los pequeños da cuenta de una verdad: que nada de lo que una vez haya acontecido ha de darse por perdido para la historia. Pero solo a la humanidad redimida le es dado por completo su pasado. Lo cual quiere decir: solo para la humanidad redimida se ha hecho su pasado citable en cada uno de sus momentos. Cada uno de los instantes vividos se convierte en una citation à l'ordre du jour, pero precisamente para el día del Juicio Final. (Benjamin, 2018, pág. 308)

Esto hace pensar varias cosas. Nuestro pasado aún no es citable, pues está en un proceso que, desde muchos sectores políticos, se ha intentado neutralizar. Aún no nos hemos redimido si no comprendemos la barbarie a la que sometemos a nuestro país diariamente. La indolencia permanecerá como patología de una sociedad que aún no es capaz de apropiarse de su historia y esto no quiere significar otra cosa que querer apropiarse de sí misma. Por eso todos los momentos vividos, cada instante, cada pequeño acto donde se manifiesta el desprecio, la indolencia, la ignorancia y el socavamiento del reconocimiento, son una citation à l'ordre du jour, pero acá el juicio final llegará sin la esperanza de un futuro mejor si continuamos ignorando nuestra historia, ignorándonos a nosotros mismos. 


\section{La voz del cueppo Valentina López Agudelo}

Las marcas sobre el cuerpo del otro, desde la época de las colonizaciones europeas, han retratado el rostro simbólico y físico de la violencia. Colonizar un territorio puede tener entonces en principio dos momentos. En el primero se tatúa brutalmente la piel del otro, el hogar más cercano. En el segundo es en donde se tatúan violentamente las tierras, pues estas son el primer espacio en el cual se configura la vida. La violencia tiene la intención de dejar huellas que narren la tortura, el asesinato, los destierros. Colombia ha sido una morada para relatar estas historias, ha vivido sumergida durante su larga vida como nación en conflictos que atentan contra el cuerpo y el territorio de los sujetos. La historia del conflicto armado contemporáneo es solo la representación de la barbarie por medio de un mismo imaginario colonizador.

\section{El cuerpo que narpa}

No hace falta escuchar gritos para saber que las historias que han vivido los colombianos se conocen en silencio. Las experiencias más traumáticas permanecen siempre ocultas a la voz, pero visibles en la piel. Un cuerpo que ha sobrevivido a la violencia es inquietante por mudo, pero a su vez, se puede sentir desde lo lejos el aroma que deja la experiencia del miedo, el odio aún no combatido, las injusticas y la impunidad.

\section{Territorios que palpitan}

Esta larga lucha que hasta el día de hoy vive el país directa e indirectamente deja un baúl de memorias que se hace necesario indagar y conocer. Los territorios fueron los primeros en sufrir igualmente las marcas de la guerra. Estos lugares que también palpitan sintieron, como los cuerpos, las violaciones dentro de sus regiones y departamentos. Por ello, se hace necesario conversar con las huellas, con las voces silenciadas, con las tierras como testigos. El largo tránsito del conflicto no expone solo una historia con una única Verdad. Existen narraciones e historias incompletas que, en cambio, sí perduran y se cuentan a través de los tatuajes que se dejaron sobre los cuerpos, sobre sus objetos más cercanos, sobre sus hogares. Los cuerpos mutilados, las tierras infértiles dejaron, aunque nostálgicos, paisajes que permitieron dimensionar la magnitud de los daños, de los odios, lo que se causó y se sigue causando. Solo falta mirar a las víctimas, ojear los paisajes en detalle para comenzar a entender el universo de sufrimientos en el que ha estado sumergido el país a lo largo de la historia. 


\section{El país desconocido \\ Andrea España Carreño}

Siempre he dicho que de nuestra amada Colombia solo se conoce un pedacito, lo que es común, en lo que encaja la moda, lo que nos representa en el mundo y lo que nos hace grande como país. Grandeza que debemos rectificar cuidadosamente.

Leer a Molano ha hecho que mi percepción cambie y se reconstruya; no solo porque no es cierta en su totalidad, sino porque es de los pocos autores de la historia de nuestro país que nos muestra esa otra Colombia que olvidamos hace mucho y que es en realidad la que nos hace verdaderamente grandes.

Marquetalia es una vereda del sur del departamento de Tolima con una riqueza natural valiosa y uno de los lugares que más olvidados hemos tenido. Solo recordamos eso que la violencia ha hecho que se resalte de ella. Molano afirma en cada uno de sus escritos que es una tierra rica en caudales de agua, por sus ríos y riveras que la hacen ser todavía una tierra con increíbles atributos. Allí se siembra gran parte de los productos que consumimos y que, a su vez, el gobierno no reconoce en ella la importancia que realmente tiene.

A lo largo de la lectura de la obra A lomo de mula. Viaje al corazón de las Farc, me pregunto, por una parte, por qué ese nombre. Pensé encontrarme esa frase muchas veces, pero no fue así. A lomo de mula, hace referencia a la forma en la que se construyó nuestro campo y cómo Molano recorrió las tierras para recolectar información que le permitiera elaborar los textos que hoy leemos. El autor lo que hace, más allá de mostrarnos el olvido de nuestra tierra, es contarnos por qué ha sucedido y que es solo responsabilidad nuestra que eso cambie. Ya basta con que la violencia sea lo que nos representa. Somos más que eso, somos un país que le duele el otro y no está dispuesto a seguir en una guerra sin sentido.

\section{Referencias}

Benjamin, W. (2018). Iluminaciones. Bogotá, Colombia: Taurus.

Molano, A. (2016). A lomo de mula. Viaje al corazón de las FARC. Bogotá, Colombia: Aguilar. 